\title{
Effect of KI-67 positive cellular index on prognosis after hepatectomy in Barcelona Clinic Liver Cancer stage A and B hepatocellular carcinoma with microvascular invasion
}

This article was published in the following Dove Press journal: OncoTargets and Therapy

\author{
Hong-Hao $\mathrm{Li}^{1}, *$ \\ Lu-Nan $\mathrm{Qi}^{1-3, *}$ \\ Liang $\mathrm{Ma}^{1,2}$ \\ Zu-Shun Chen' \\ Bang-De Xiang ${ }^{1-3}$ \\ Le-Qun $\mathrm{Li}^{1-3}$ \\ 'Department of Hepatobiliary \\ Surgery, Affiliated Tumor Hospital \\ of Guangxi Medical University, \\ Nanning, 530021, China; ${ }^{2}$ Guangxi \\ Liver Cancer Diagnosis and Treatment \\ Engineering and Technology Research \\ Center, Nanning, 53002I, China; \\ ${ }^{3}$ Key Laboratory of Early Prevention \\ and Treatment for Regional High \\ Frequency Tumor, Ministry of \\ Education, Nanning, 53002I, China \\ *These authors contributed equally \\ to this work
}

\begin{abstract}
Objective: This study aimed to explore the relationship between KI-67 positive cellular index and recurrence-free survival (RFS) in Barcelona Clinic Liver Cancer (BCLC) stage A and B hepatocellular carcinoma (HCC) patients, particularly those with microvascular invasion (MVI).

Methods: A total of 333 patients who underwent curative hepatectomy had their immunohistochemistry analyzed retrospectively for KI-67 positive cellular index.

Results: In total, 41.1\% (137/333) of HCC patients displayed high KI-67 positive cellular index $(>35 \%)$. Patients with high KI-67 positive cellular index had poorer RFS than those with low index $(P<0.0001)$. Patients were then subdivided into an MVI positivity group $(\mathrm{n}=192)$ and an MVI negativity group ( $n=141)$. In the MVI positivity group, patients with high KI-67 positive cellular index had a shorter RFS after operation as compared to those with low index $(P<0.0001)$. However, there was no significant difference in RFS between high- and low-index subgroups within the MVI negativity group $(P>0.05)$. Additionally, patients with high KI-67 positive cellular index combined with MVI positivity had the shortest RFS of all those with MVI negativity, regardless of KI-67 cellular index level $(P<0.0001)$. Multivariate analysis showed that node number $>1$, capsule absence, high KI-67 positive cellular index, and alphafetoprotein $>400 \mathrm{ng} / \mathrm{mL}$ were independent risk factors for a recurrence of HCC with MVI.

Conclusion: Our results suggested that high KI-67 positive cellular index may represent a poor prognostic factor in BCLC stage A and B HCC patients, especially those with MVI.
\end{abstract}

Keywords: hepatocellular carcinoma, KI-67, microvascular invasion, prognosis, BCLC stage A and B, hepatectomy

\section{Introduction}

$\mathrm{HCC}$ is one of the most common malignant tumors and the second most common cause of cancer death according to the World Cancer Report 2014. ${ }^{1}$ Although there are numerous classification systems for HCC, the BCLC staging system is the most widely used because of its simplicity and clear treatment guidelines for patients at different stages of disease. ${ }^{2,3}$ Survival outcomes in selected patients who show no portal vein tumor thrombus and symptoms of portal hypertension with BCLC stage A or B classification undergoing hepatectomy for HCC are continuously improved. ${ }^{4-6}$

The most commonly recommended treatment for most HCC patients is hepatectomy; however, it is estimated that $50 \%-60 \%$ of $\mathrm{HCC}$ patients even including those in early BCLC stage A experience postoperative disease recurrence within 3 years. ${ }^{7-10}$ MVI is considered to be an important clinicopathological feature of recurrence and has been
Correspondence: Le-Qun Li Department of Hepatobiliary Surgery, Affiliated Tumor Hospital of Guangxi Medical University, Number 7I Hedi Road, Nanning, 53002I, Guangxi, China Tel +86 77l 53I 0045

$\mathrm{Fax}+8677 \mid 535003$ I

Email li_lequn@263.net 
given broad attention in the academic field as an important prognostic risk factor. ${ }^{11-14}$ Numerous studies have focused on preoperative predictive factors in the presence of MVI..$^{15-17}$ Recently, an investigation has demonstrated that MVI may be a factor predicting micro-metastasis in the liver parenchyma. Patients who had more than five vessels affected by MVI were shown to have such metastasis. ${ }^{18}$ The majority of HCC cases with MVI have a poor prognosis; however, several HCC patients with MVI have been shown to have long-term survival. ${ }^{19}$ Thus, the mechanism by which MVI might lead to postoperative recurrence deserves further exploration.

$\mathrm{KI}-67$ is well known to have an important influence on all phases of the cell cycle, except G0 phase, and is often considered a marker of cellular proliferation. ${ }^{20,21} \mathrm{KI}-67$ has a close relationship with breast cancer, but has also been examined as a predictor of postoperative recurrence for several types of tumors, including HCC. ${ }^{22,23}$ Several reports have indicated that the increase in growth fraction of hepatocytes could exert a considerable influence on hepatocarcinoma and KI-67 positive cellular index is the highest in $\mathrm{HCC}$ but lowest in normal liver tissue. ${ }^{24,25}$ The influence of KI-67 on HCC prognosis has been debated, but several investigations suggest KI-67 is not a poor prognostic factor. ${ }^{22,26,27}$ The aim of this study was to explore the risk patterns of recurrence for patients who underwent hepatic resection for BCLC stage A and B HCC and to validate the relationship between KI-67 positive cellular index and RFS for BCLC stage A and B HCC patients.

\section{Materials and methods Patients}

From March 2012 to May 2017, 333 patients undergoing $\mathrm{R} 0$ resection at our hospital were enrolled. Inclusion criteria were as follows: 1) R0 resection, defined as complete macroscopic removal of the tumor, where the resection margin was negative and no detectable intrahepatic or extrahepatic metastasis lesions remained; 2) presence of disease staged as BCLC stage A or B; 3) definitive pathological diagnosis of HCC based on the WHO criteria; 4) no radiotherapy or chemotherapy was received before operation; 5) liver function was within Child-Pugh A stage and performance status test score was $0-1$; and 6) tumor differentiation grade was identified according to Edmondson-Steiner criteria. ${ }^{28}$ Criteria for MVI were as follows: 1) tumor thrombus partially or totally covered by endothelium and visible only on microscopy; and 2) endothelium-covered tumor thrombus was inside the tumor or situated closely to the tumor edge and must be extended to the portal vein or hepatic vein branches to be considered as MVI. ${ }^{14}$

\section{Follow-up}

Patients were followed up every 1-2 months in the first year and every 3 months afterward. Ultrasonography and computed tomography/magnetic resonance imaging were used for examination, and serum AFP was examined regularly. Recurrence was proven with one of the following criteria: 1) a significant rise in AFP combined with one typical imaging modality; 2) at least two types of imaging showed a lesion simultaneously; and 3) a lesion biopsy performed due to new recurrence. Final time to recurrence was evaluated by clinical doctors, and recurrence was classified as either intrahepatic or extrahepatic. The last follow-up data included in this study were collected on December 1, 2017.

\section{Immunohistochemistry}

Staining was performed using an IHC kit. Sections were regularly dewaxed by dimethylbenzene, dehydrated by gradient concentration alcohol, and then immersed in sodium citrate buffer $(2,000 \mathrm{~mL}, 0.01 \mathrm{M}, \mathrm{pH} 6.0)$ at $100^{\circ} \mathrm{C}$. Endogenous peroxidase activity and unspecific reactions were blocked with $3 \%$ hydrogen peroxide and normal goat serum, respectively. The sections were incubated with anti-KI-67 antibody overnight at $4{ }^{\circ} \mathrm{C}$ and then treated with biotinylated anti-rabbit immunoglobulin and streptavidin conjugated to horseradish peroxidase for 30 minutes at room temperature. Diaminobenzidine substrate was used for stain development, and sections were counterstained with hematoxylin and sealed with neutral balsam. Sections lacking primary antibody were used as negative controls. ${ }^{23,29}$

IHC results were analyzed by a trained pathologist in the pathology department at our hospital. KI-67 positive cellular index was described as the presence of nuclear staining. All stained nuclei were scored as positive regardless of the intensity of staining. Cell counts were made at $\times 100$ magnification with a conventional light microscope in five randomly selected fields. The percentage of cells expressing KI-67 was determined by counting 1,000 cells/slide. KI-67labeled cell counting was evaluated by a trained pathologist in the pathology department at our hospital. Computational formula was as follows: ${ }^{30,31}$

Number of IHC-positive cells (KI - 67)*100

Total number of cells observed

\section{Statistical analysis}

All statistical analyses were performed with SPSS version 23. The chi-squared or Fisher's exact test was used for evaluating discrete data. RFS curves were created using KaplanMeier method and compared employing a log-rank test. 
Independent postoperative recurrence risk factors were evaluated using the Cox proportional hazard model. Two-tailed $P<0.05$ was considered statistically significant.

\section{Ethics statement}

This study was conducted in accordance with the Declaration of Helsinki guidelines and was approved by the Institutional Review Board of Affiliated Tumor Hospital of Guangxi Medical University. Written informed consent was provided by all voluntary participants for their clinical records to be used in this study. Additionally, the tissue specimens for IHC were used after obtaining written consent from all patients.

\section{Results}

\section{Patient characteristics}

All the patient characteristics are summarized in Table 1. The median patient age was 48 years $(48.39 \pm 0.58)$. The positivity rates for HBsAg and HBV DNA were $86.4 \%$ and

Table I Clinical characteristics

\begin{tabular}{|c|c|}
\hline Age (years), mean \pm SD (range) & $48.4 \pm 0.58(29-79)$ \\
\hline \multicolumn{2}{|l|}{ Sex } \\
\hline Male, n (\%) & $284(85.3 \%)$ \\
\hline Female, n (\%) & $49(14.7 \%)$ \\
\hline \multicolumn{2}{|l|}{$\mathrm{HBsAg}$} \\
\hline Positive, n (\%) & $288(86.4 \%)$ \\
\hline Negative, n (\%) & $45(13.6 \%)$ \\
\hline \multicolumn{2}{|l|}{ HBV DNA } \\
\hline$>500$ copies/mL, n (\%) & $232(69.7 \%)$ \\
\hline$\leq 500$ copies/mL, n (\%) & $101(30.3 \%)$ \\
\hline \multicolumn{2}{|l|}{ AFP } \\
\hline$>400$ ng/mL, n (\%) & 165 (49.5\%) \\
\hline$\leq 400$ ng/mL, n (\%) & $168(50.5 \%)$ \\
\hline \multicolumn{2}{|l|}{ Tumor size } \\
\hline$>5 \mathrm{~cm}, \mathrm{n}(\%)$ & $195(58.6 \%)$ \\
\hline$\leq 5 \mathrm{~cm}, \mathrm{n}(\%)$ & $138(42.4 \%)$ \\
\hline \multicolumn{2}{|l|}{ Edmondson stage } \\
\hline Low, n (\%) & $223(67.0 \%)$ \\
\hline High, n (\%) & 110 (33.0\%) \\
\hline \multicolumn{2}{|l|}{ Node number } \\
\hline Single, n (\%) & 235 (70.6\%) \\
\hline Multiple, n (\%) & $98(29.4 \%)$ \\
\hline \multicolumn{2}{|l|}{ Capsule } \\
\hline Complete, n (\%) & $249(74.8 \%)$ \\
\hline Absent, n (\%) & $84(25.2 \%)$ \\
\hline \multicolumn{2}{|l|}{ Cirrhosis degree } \\
\hline Low, n (\%) & $222(66.7 \%)$ \\
\hline High, n (\%) & $111(33.3 \%)$ \\
\hline \multicolumn{2}{|l|}{ MVI } \\
\hline Positivity, n (\%) & I9I (57.4\%) \\
\hline Negativity, n (\%) & $142(42.6 \%)$ \\
\hline \multicolumn{2}{|l|}{$\mathrm{KI}-67$ positive cellular index } \\
\hline High, n (\%) & I37 (4I. I\%) \\
\hline Low, n (\%) & $196(58.9 \%)$ \\
\hline
\end{tabular}

Abbreviations: AFP, alpha-fetoprotein; $\mathrm{HBsAg}$, serum hepatitis $B$ surface antigen; HBV DNA, hepatitis B virus DNA levels; MVI, microvascular invasion.
$69.7 \%$, respectively. Rates for patients with AFP $>400 \mathrm{ng} /$ $\mathrm{mL}$ and tumor size $>5 \mathrm{~cm}$ were $49.5 \%$ and $58.6 \%$, respectively. There were $223(67.0 \%)$ and 222 (66.7\%) patients determined to have low Edmondson and cirrhosis stages, respectively. Additionally, absent capsule was shown in 84 (25.2\%) patients and MVI was detected in $192(57.7 \%)$ cases and not detected in 141 (42.3\%) cases.

\section{$\mathrm{IHC}$ for $\mathrm{KI}-67$}

A total of 333 patients were detected to have KI-67 positive cellular index with immmunohistochemical staining, with positive cellular index ranging from $2 \%$ to $97 \%$. The median positive cellular index was $35 \%(34.52 \% \pm 1.24 \%)$, which was considered to be the cutoff value for the following analysis. KI-67 positive cellular index was considered to be high if there was a $>35 \% \mathrm{KI}-67$ positive cellular index or low at $\leq 35 \%$ KI-67 positive cellular index (Figure 1A and B). Accordingly, 137 patients (41.1\%) had a high KI-67 positive cellular index and 196 patients (58.9\%) had a low KI-67 positive cellular index.

Then, 40 adjacent non-tumorous tissues ( 20 from patients with high KI-67 positive cell index and 20 from patients with low KI-67 positive cell index) were selected. Estimates of KI-67 positive cellular index ranged from $0 \%$ to $10 \%$ in adjacent non-tumorous tissues. Significant difference in KI-67 was observed between HCC tissues and adjacent non-tumorous tissues $(P<0.001)$. A representative example is shown in Figure $1 \mathrm{C}$.

\section{Prognostic significance of $\mathrm{KI}-67$ positive cellular index in HCC}

By the end of follow-up, 231 of 333 patients (69.4\%) had developed recurrence. Median RFS was 18 months, and the 1-, 2-, and 3-year RFS were $61.5 \%, 45.5 \%$, and $32.8 \%$, respectively, for all patients. For patients with high and low KI-67 positive cell index, the 1-, 2-, and 3-years RFS were $77.5 \%, 59.2 \%$, and $44.0 \%$ and $38.6 \%, 24.7 \%$, and $16.1 \%$, respectively. Kaplan-Meier analysis revealed that patients with high KI-67 positive cellular index had a poorer RFS (median: 7 months vs 31 months) after hepatectomy compared with those with low KI-67 positive cellular index $(P<0.001)$ (Figure 2).

Table 2 shows the univariate and multivariate Cox regression analyses of operative factors associated with postoperative HCC recurrence. In univariate analysis, age $>48$ years, positive $\mathrm{HBsAg}$, AFP $>400 \mathrm{ng} / \mathrm{mL}$, tumor size $>5 \mathrm{~cm}$, MVI positivity, and high KI-67 positive cellular index were associated with postoperative recurrence. Multivariate analysis demonstrated high KI-67 positive cellular index 


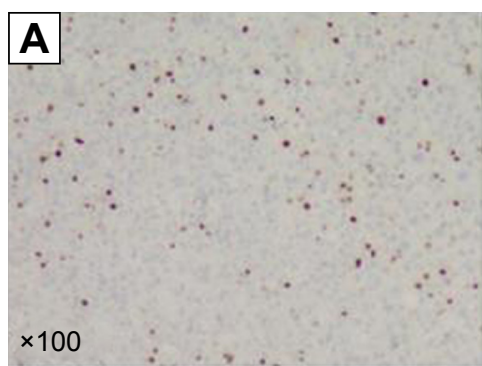

Low in tumor

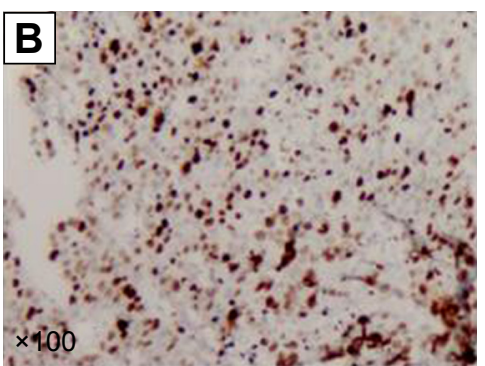

High in tumor

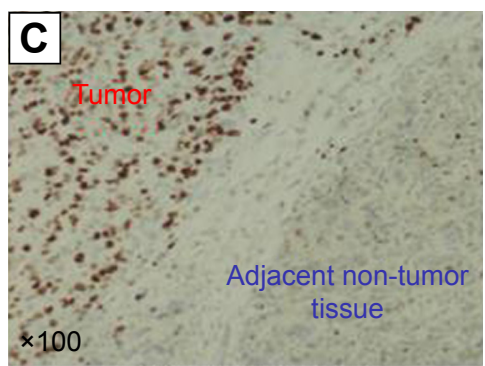

Low in adjacent tissue but high in tumor

Figure I Pathologically, primary cellular carcinoma of the liver (H\&E, $\times 100)$ : (A) proportion of positive cellular index $\leq 35 \%$ and $(\mathbf{B})$ proportion of positive cellular index $>35 \%$. (C) Representative image showing significant differences in KI-67 positive cellular index between HCC tissues and adjacent non-tumor tissues. Note: KI-67 positive cellular index was defined as the presence of nuclear staining. Abbreviation: HCC, hepatocellular carcinoma.

(HR: $2.13,95 \%$ CI: $1.62-2.80, P<0.001)$, AFP $>400 \mathrm{ng} / \mathrm{mL}$ (HR: $1.46,95 \%$ CI: $1.11-1.92, P=0.007)$, tumor size $>5 \mathrm{~cm}$ (HR: $1.37,95 \% \mathrm{CI}: 1.03-1.83, P=0.031$ ), number of nodes $>1$ (HR: $1.99,95 \%$ CI: 1.50-2.66, $P<0.001$ ), absent capsule (HR: $2.89,95 \%$ CI: $2.15-3.90, P<0.001$ ), and MVI positivity (HR: 1.80, 95\% CI: 1.33-2.42, $P<0.001$ ) were independent risk factors for postoperative recurrence.

\section{Comparisons of $\mathrm{KI}-67$ expression in HCC patients with and without MVI}

For this analysis, 333 patients were subdivided into an MVI positivity group $(\mathrm{n}=192)$ and an MVI negativity group $(n=141)$. The MVI positivity group had a higher rate of high KI-67 positive cellular index, as compared to the MVI negativity group $(54.7 \%$ vs $22.7 \%, P<0.001)$. Kaplan-Meier method was utilized to analyze the correlation between KI-67 positive cellular index and the prognosis of HCC with MVI.

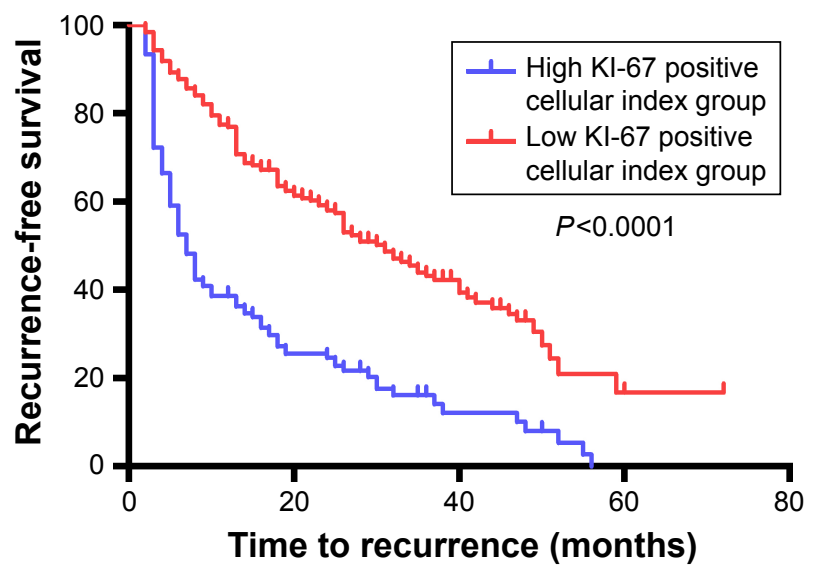

Figure 2 Comparison of the recurrence-free survival curves between high KI-67 group and low KI-67 group.

Notes: Results are from Kaplan-Meier analysis. $P<0.05$ was considered to be statistically significant.
As the survival curves shown in Figure 3A, in the MVI positivity group, patients with high KI-67 positive cellular index had a shorter RFS after operation compared with low KI-67 positive cellular index patients (median: 5 months vs 26 months, $P<0.001)$. However, there was no significant difference in RFS between high KI-67 positive cellular index and low KI-67 positive cellular index subgroups observed in MVI negativity group $(P>0.05)$ (Figure 3B). Furthermore, patients with high KI-67 positive cellular index combined with MVI positivity had the shortest RFS of all those with MVI negativity, regardless of high or low KI-67 positive cellular index level $(P<0.0001)$ (Figure 3C and D). However, there was no significant difference in RFS between patients with low KI-67 positive cellular index combined with MVI positivity and all those with MVI negativity, regardless of high or low KI-67 positive cellular index level $(P>0.05)$ (Figure 3E and F).

\section{Analysis of predictive factors for $\mathrm{HCC}$ with MVI}

The clinical characteristics of patients with MVI were analyzed. In our study population comprising 333 patients, 192 (57.7\%) had MVI-positive HCC. Baseline patient characteristics were compared between the MVI positivity group and MVI negativity group (Table 3). During follow-up, 149 (77.6\%) patients in the MVI positivity group and 59 patients (41.8\%) in the MVI negativity group experienced recurrence. Upon univariate analysis, patients who had a high index had a significantly higher risk of recurrence after surgery compared to patients with a low index (HR: 2.13, 95\% CI: 1.49-3.03, $P<0.001)$. Multivariate Cox analysis showed that high KI-67 positive cellular index was also a significant, independent predictor of recurrence after surgery (HR: 2.72, $P<0.001$ ) (Table 4). 
Table 2 Factors associated with postoperative recurrence in $\mathrm{HCC}$

\begin{tabular}{|c|c|c|c|}
\hline \multirow[t]{2}{*}{ Variables } & \multirow{2}{*}{$\begin{array}{l}\text { Univariate } \\
\text { analysis } \\
P \text {-value }\end{array}$} & \multicolumn{2}{|l|}{$\begin{array}{l}\text { Multivariate } \\
\text { Cox analysis }\end{array}$} \\
\hline & & HR (95\% Cl) & $P$-value \\
\hline $\begin{array}{l}\text { Age (years) } \\
\quad>48 \\
\quad \leq 48\end{array}$ & 0.011 & $0.90(0.68-1.18)$ & 0.44 \\
\hline $\begin{array}{l}\text { Sex } \\
\qquad \text { Male } \\
\text { Female }\end{array}$ & 0.916 & & \\
\hline $\begin{array}{l}\mathrm{HBsAg} \\
\text { Positive } \\
\text { Negative }\end{array}$ & 0.002 & $1.66(0.98-2.80)$ & 0.60 \\
\hline $\begin{array}{l}\text { Edmondson } \\
\text { Low stage } \\
\text { High stage }\end{array}$ & 0.861 & & \\
\hline $\begin{array}{l}\operatorname{AFP}(\mathrm{ng} / \mathrm{mL}) \\
\quad>400 \\
\quad \leq 400\end{array}$ & 0.023 & $1.46(1.11-1.92)$ & 0.007 \\
\hline $\begin{array}{l}\text { Tumor size }(\mathrm{cm}) \\
>5 \\
\leq 5\end{array}$ & 0.023 & $1.37(1.03-1.83)$ & 0.031 \\
\hline $\begin{array}{l}\text { HBV DNA (copies } / \mathrm{mL}) \\
\quad>500 \\
\quad \leq 500\end{array}$ & 0.045 & $0.92(0.65-1.32)$ & 0.67 \\
\hline $\begin{array}{l}\text { Node number } \\
\text { Single } \\
\text { Multiple }\end{array}$ & $<0.001$ & $1.99(1.50-2.66)$ & $<0.00 \mathrm{I}$ \\
\hline $\begin{array}{l}\text { Capsule } \\
\text { Absent } \\
\text { Complete }\end{array}$ & $<0.001$ & $2.89(2.15-3.90)$ & $<0.001$ \\
\hline $\begin{array}{l}\text { Cirrhosis } \\
\text { Moderate or high } \\
\text { Low }\end{array}$ & 0.207 & & \\
\hline $\begin{array}{l}\text { MVI } \\
\text { Positivity } \\
\text { Negativity }\end{array}$ & $<0.001$ & $1.80(1.33-2.42)$ & $<0.001$ \\
\hline $\begin{array}{l}\text { KI-67 positive cellular index } \\
\text { High } \\
\text { Low }\end{array}$ & $<0.001$ & $2.13(1.62-2.80)$ & $<0.001$ \\
\hline $\begin{array}{l}\text { Surgical margin }(\mathrm{cm}) \\
\qquad 1 \\
>1\end{array}$ & 0.512 & & \\
\hline
\end{tabular}

Abbreviations: AFP, alpha-fetoprotein; $\mathrm{HBsAg}$, serum hepatitis $B$ surface antigen; HBV DNA, hepatitis B virus DNA levels; HCC, hepatocellular carcinoma; HR, hazard ratio; MVI, microvascular invasion.

\section{Discussion}

Currently, the prognosis for HCC patients after radical hepatic resection is not as satisfactory as would be expected. ${ }^{32,33}$ To facilitate the timely detection of $\mathrm{HCC}$ recurrence, clinical predictors of disease events are urgently needed to be identified. In our study, we demonstrated that a high level of KI-67 positive cellular index, and AFP $>400 \mathrm{ng} / \mathrm{mL}$, tumor size $>5 \mathrm{~cm}$, node number $>1$, absence of capsule, and MVI positivity were independent risk factors predicting the postoperative recurrence after hepatectomy.

It has been made evident that the proliferative activity of tumors has a great impact on postoperative prognosis. ${ }^{34}$ KI-67 nuclear protein has been shown to have an important influence on all phases of the cell cycle, except the G0 phase, and is often considered to be a marker of cellular proliferation. ${ }^{21}$ Studies have confirmed that KI-67 expression could be regarded as a poor prognosis predictor in several types of cancers. For instance, high levels of KI-67 expression in distant metastatic lesions have been shown to predict a poor overall survival outcome in breast cancer; ${ }^{23}$ elevated expression of KI-67 was associated with tumor metastasis and could be employed as a prognostic factor in gastroenteropancreatic neuroendocrine tumors; ${ }^{35} \mathrm{KI}-67$ expression may play a critical role in predicting prognosis of astrocytomas and should be routinely examined in patients with astrocytomas. ${ }^{36}$ In our study, we found that the median RFS in patients with high KI-67 positive cellular index was only 7 months, while RFS reached 31 months in patients with low positive cellular index $(P<0.001)$. Thus, higher KI-67 positive cellular index could be a powerful risk factor for $\mathrm{HCC}$ recurrence following hepatectomy. Although the cutoff in our study was different from the cutoff in published reports, our result was in accordance with the trends seen in earlier investigations..$^{22}$

MVI was considered as an important clinicopathological feature of early recurrence and has been given broad attention in the academic field as an important prognostic risk factor. ${ }^{11-14}$ However, a relatively better prognosis was also displayed for some patients with high KI-67 positive cellular index. In addition, few studies have described the relative mechanism through which MVI causes postoperative recurrence. Thus, we conducted a prospective study. Interestingly, the present study demonstrated that high KI-67 positive cellular index had a clear impact on prognosis of $\mathrm{HCC}$ patients with MVI while there was no obvious influence observed in HCC patients without MVI. This novel investigation suggested that high KI-67 positive cellular index might account for poor prognosis by acting on cells undergoing MVI. In other words, we inferred that high KI-67 positive cellular index in cells undergoing MVI may promote cellular proliferation, and lead to early recurrence.

Several reports maintain that KI-67 expression is enriched in corresponding areas with microvascular density "hot spots", as they are positively correlated. ${ }^{29,37,38}$ Analogously, we found that the HCC with MVI showed higher KI-67 positive cellular index than HCC without MVI. Meanwhile, there was a higher incidence of MVI positivity in HCC patients 

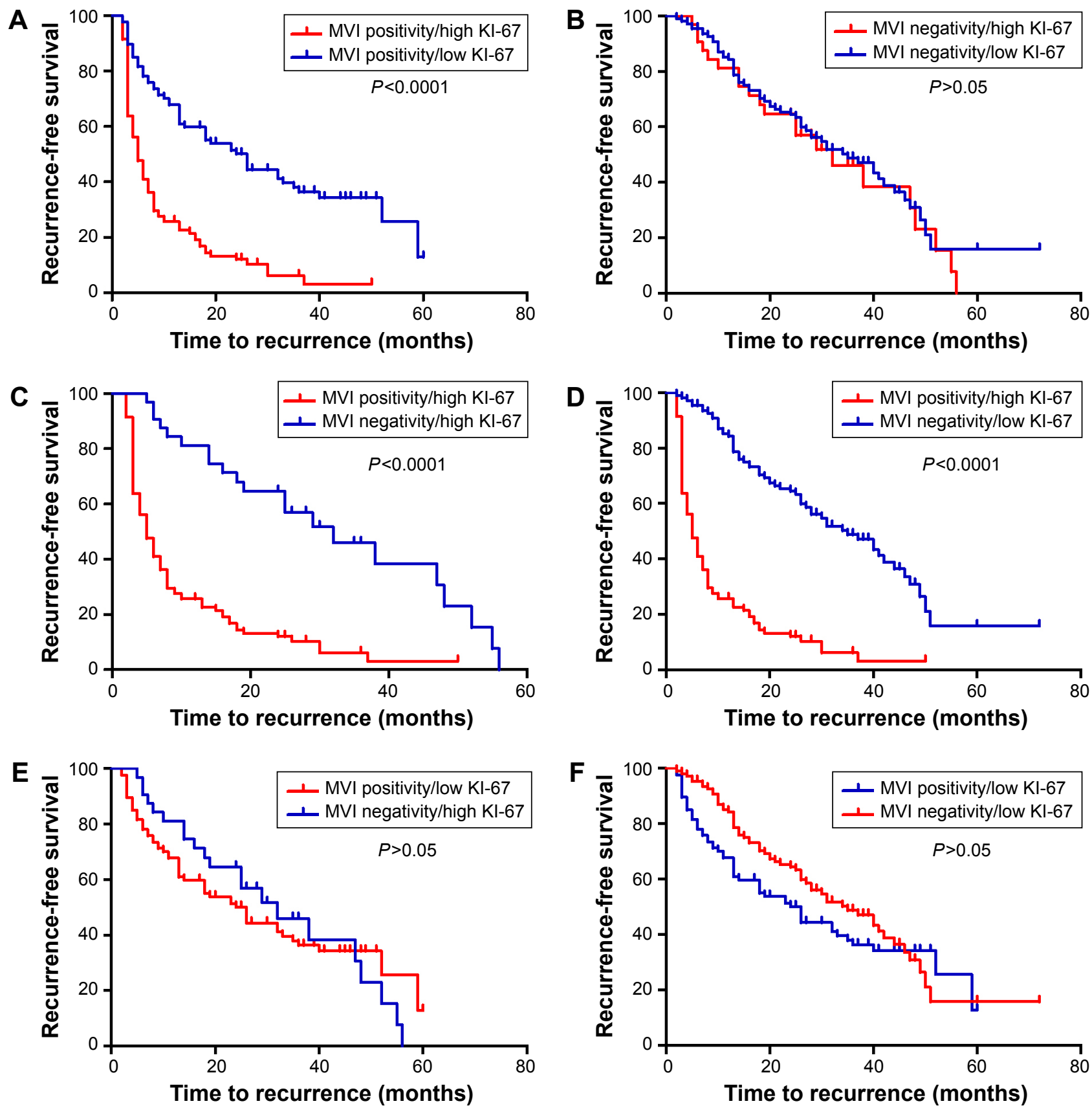

\begin{tabular}{lllll}
\hline Group & Number & RFS & & \\
\cline { 3 - 5 } & & 1-Year & 2-Year & 3-Year \\
\hline MVI positivity/high KI-67 & 105 & $25.7 \%$ & $12.0 \%$ & $6.2 \%$ \\
MVI positivity/low KI-67 & 87 & $67.8 \%$ & $51.4 \%$ & $38.0 \%$ \\
MVI negativity/high KI-67 & 32 & $81.1 \%$ & $64.6 \%$ & $46.1 \%$ \\
MVI negativity/low KI-67 & 109 & $85.2 \%$ & $64.4 \%$ & $48.8 \%$ \\
\hline
\end{tabular}

Figure 3 Comparison of the recurrence-free survival curves.

Notes: (A) Patients with MVI positivity combined with high KI-67 show shorter RFS compared with patients with MVI positivity combined with low KI-67. (B) Patients with MVI negativity combined with high KI-67 show no difference compared with patients with MVI negativity combined with low KI-67 in terms of RFS. (C) Patients with MVI positivity combined with high KI-67 show shorter RFS compared with patients with MVI negativity combined with high KI-67. (D) Patients with MVI positivity combined with high KI-67 show shorter RFS compared with patients with MVI negativity combined with low KI-67. (E) Patients with MVI positivity combined with low KI-67 show no difference compared with patients with MVI negativity combined with high KI-67 in terms of RFS. (F) Patients with MVI positivity combined with low KI-67 show no difference compared with patients with MVI negativity combined with low KI-67 in terms of RFS. MVI positivity/high KI-67: MVI positivity and high KI-67 positive cellular index; MVI positivity/low KI-67: MVI positivity and low KI-67 positive cellular index; MVI negativity/high KI-67: MVI negativity and high KI-67 positive cellular index; MVI negativity/low KI-67: MVI negativity and low KI-67 positive cellular index. Results are from Kaplan-Meier analysis. $P<0.05$ was considered to be statistically significant.

Abbreviations: MVI, microvascular invasion; RFS, recurrence-free survival. 
Table 3 Baseline characteristics between MVI positivity and MVI negativity groups

\begin{tabular}{|c|c|c|}
\hline Variables & $\begin{array}{l}\text { MVI positivity } \\
(\mathrm{n}=192)\end{array}$ & $\begin{array}{l}\text { MVI negativity } \\
(n=\mid 4 I)\end{array}$ \\
\hline Age (range) (years) & $48(29-7 I)$ & $48(29-79)$ \\
\hline Sex, male/female & $162 / 30$ & $122 / 19$ \\
\hline $\mathrm{HBs} A g$, positive/negative & $164 / 28$ & $124 / 17$ \\
\hline HBV DNA (copies $/ \mathrm{mL}$ ), $>500 / \leq 500$ & $138 / 54$ & $94 / 47$ \\
\hline $\operatorname{AFP}(\mathrm{ng} / \mathrm{mL}),>400 / \leq 400$ & $109 / 83$ & $56 / 85$ \\
\hline Tumor size $(\mathrm{cm}),>5 / \leq 5$ & $139 / 53$ & $56 / 85$ \\
\hline Edmondson stage, low/high & $126 / 66$ & $97 / 34$ \\
\hline Node number, single/multiple & $129 / 63$ & $106 / 35$ \\
\hline Capsule, incomplete/complete & $66 / 126$ & $18 / 123$ \\
\hline Cirrhosis, low/high & $133 / 59$ & $89 / 52$ \\
\hline $\mathrm{KI}-67$ expression, high/low & $105 / 87$ & $32 / 109$ \\
\hline
\end{tabular}

Abbreviations: AFP, alpha-fetoprotein; $\mathrm{HBsAg}$, serum hepatitis $B$ surface antigen; HBV DNA, hepatitis B virus DNA levels; MVI, microvascular invasion.

with high KI-67 positive cellular index than in those with low KI-67 positive cellular index. However, a direct relationship between MVI positivity and KI-67 positive cellular index should be demonstrated and requires further exploration.

Certainly, there were some limitations to this study. Firstly, the immunohistochemical positivity and the cutoff values used in our study could be controversial because these results were not collected or analyzed in previous studies. ${ }^{22}$ Next, we were not able to clarify the relationship between MVI and KI-67 positive cellular index because we analyzed the results from a clinical standpoint. However, we clearly found that highly positive KI-67 cellular index had a clear impact on HCC patients with MVI while no obvious influence was observed in HCC patients without MVI in terms of RFS.

Table 4 Factors associated with postoperative recurrence in $\mathrm{HCC}$ with MVI

\begin{tabular}{|c|c|c|c|}
\hline \multirow[t]{2}{*}{ Variables } & \multirow{2}{*}{$\begin{array}{l}\begin{array}{l}\text { Univariate } \\
\text { analysis }\end{array} \\
P \text {-value }\end{array}$} & \multicolumn{2}{|l|}{$\begin{array}{l}\text { Multivariate } \\
\text { analysis }\end{array}$} \\
\hline & & HR $(95 \% \mathrm{Cl})$ & $P$-value \\
\hline Age $>48$ years & 0.105 & & \\
\hline Sex: male & $0.54 I$ & & \\
\hline Positive $\mathrm{HBsAg}$ & 0.029 & $1.16(0.70-1.94)$ & 0.60 \\
\hline Low Edmondson stage & 0.168 & & \\
\hline AFP $>400 \mathrm{ng} / \mathrm{mL}$ & 0.025 & $1.78(\mathrm{I} .26-2.5 \mathrm{I})$ & 0.001 \\
\hline Tumor size $>5 \mathrm{~cm}$ & 0.662 & & \\
\hline HBV DNA >500 copies $/ \mathrm{mL}$ & 0.133 & & \\
\hline Node number $>$ I & $<0.001$ & $2.13(1.49-3.03)$ & $<0.001$ \\
\hline Absent capsule & $<0.001$ & $3.03(2.12-4.33)$ & $<0.00 \mathrm{I}$ \\
\hline Moderate or high cirrhosis & 0.114 & & \\
\hline High KI-67 expression & $<0.001$ & $2.48(1.73-3.56)$ & $<0.001$ \\
\hline Surgical margin $<\mathrm{I} \mathrm{cm}$ & 0.342 & & \\
\hline
\end{tabular}

Abbreviations: AFP, alpha-fetoprotein; $\mathrm{HBsAg}$, serum hepatitis $B$ surface antigen; HBV DNA, hepatitis B virus DNA levels; HCC, hepatocellular carcinoma; HR, hazard ratio; $\mathrm{MVI}$, microvascular invasion.
Conclusion

Highly positive cellular index for KI-67, and AFP $>400 \mathrm{ng} / \mathrm{mL}$, tumor size $>5 \mathrm{~cm}$, node number $>1$, capsule absence, and MVI positivity are independent risk factors predicting postoperative cancer recurrence after hepatectomy. Moreover, the overexpression of KI-67 might promote disease recurrence after hepatectomy in BCLC stage A and B HCC patients, especially those with MVI. Further in-depth prospective studies are required to elucidate such a mechanism.

\section{Abbreviations}

AFP, alpha-fetoprotein; BCLC, Barcelona Clinic Liver Cancer; HBsAg, serum hepatitis B surface antigen; HBV DNA, hepatitis B virus DNA levels; HCC, hepatocellular carcinoma; HR, hazard ratio; IHC, immunohistochemistry; MVI, microvascular invasion; RFS, recurrence-free survival

\section{Acknowledgments}

This work was supported by the National Natural Science Foundation of China (NSFC grants 81502533 and 81072321) and Guangxi Natural Science Foundation grants (2013GXNSFBA019196 and GKZ201046).

\section{Author contributions}

All authors contributed toward data analysis, drafting and critically revising the paper, gave final approval of the version to be published, and agree to be accountable for all aspects of the work.

\section{Disclosure}

The authors report no conflicts of interest in this work.

\section{References}

1. Keating GM. Sorafenib: A Review in Hepatocellular Carcinoma. Target Oncol. 2017;12(2):243-253.

2. Bruix J, Sherman M, American Association for the Study of Liver Diseases. Management of hepatocellular carcinoma: an update. Hepatology. 2011;53(3):1020-1022

3. European Association For The Study Of The Liver, European Organisation For Research And Treatment Of Cancer. EASL-EORTC clinical practice guidelines: management of hepatocellular carcinoma. $J$ Hepatol. 2012;56(4):908-943.

4. Bruix J, Llovet JM. Prognostic prediction and treatment strategy in hepatocellular carcinoma. Hepatology. 2002;35(3):519-524.

5. Fan ST, Mau Lo C, Poon RT, et al. Continuous improvement of survival outcomes of resection of hepatocellular carcinoma: a 20-year experience. Ann Surg. 2011;253(4):745-758

6. Bell R, Pandanaboyana S, Lodge JPA, Prasad KR, Jones R, Hidalgo E. Primary liver resection for patients with cirrhosis and hepatocellular carcinoma: the role of surgery in BCLC early (A) and intermediate stages (B). Langenbecks Arch Surg. 2017;402(4):575-583.

7. Llovet JM, Fuster J, Bruix J. Intention-to-treat analysis of surgical treatment for early hepatocellular carcinoma: resection versus transplantation. Hepatology. 1999;30(6):1434-1440. 
8. Shim JH, Jun MJ, Han S, et al. Prognostic nomograms for prediction of recurrence and survival after curative liver resection for hepatocellular carcinoma. Ann Surg. 2015;261(5):939-946.

9. Zhang ZM, Zhang YM, Yao F, et al. Analysis on Postoperative Efficacy of Radical Hepatectomy for Patients with Non-HBV/HCV Hepatocellular Carcinoma. Asian Pac J Cancer Prev. 2015;16(8):3479-3483.

10. Tabrizian P, Jibara G, Shrager B, Schwartz M, Roayaie S. Recurrence of hepatocellular cancer after resection: patterns, treatments, and prognosis. Ann Surg. 2015;261(5):947-955.

11. Roayaie S, Blume IN, Thung SN, et al. A system of classifying microvascular invasion to predict outcome after resection in patients with hepatocellular carcinoma. Gastroenterology. 2009;137(3):850-855.

12. Kondo K, Chijiiwa K, Makino I, et al. Risk factors for early death after liver resection in patients with solitary hepatocellular carcinoma. J Hepatobiliary Pancreat Surg. 2005;12(5):399-404.

13. Sumie S, Kuromatsu R, Okuda K, et al. Microvascular invasion in patients with hepatocellular carcinoma and its predictable clinicopathological factors. Ann Surg Oncol. 2008;15(5):1375-1382.

14. Rodríguez-Perálvarez M, Luong TV, Andreana L, Meyer T, Dhillon AP, Burroughs AK. A systematic review of microvascular invasion in hepatocellular carcinoma: diagnostic and prognostic variability. Ann Surg Oncol. 2013;20(1):325-339.

15. Liu M, Wang L, Zhu H, et al. A Preoperative Measurement of Serum MicroRNA-125b May Predict the Presence of Microvascular Invasion in Hepatocellular Carcinomas Patients. Transl Oncol. 2016;9(3): $167-172$.

16. Hyun SH, Eo JS, Song BI, et al. Preoperative prediction of microvascular invasion of hepatocellular carcinoma using ${ }^{18} \mathrm{~F}-\mathrm{FDG}$ PET/CT: a multicenter retrospective cohort study. Eur J Nucl Med Mol Imaging. 2018;45(5):720-726.

17. Wang WT, Yang L, Yang ZX, et al. Assessment of Microvascular Invasion of Hepatocellular Carcinoma with Diffusion Kurtosis Imaging. Radiology. 2018;286(2):571-580.

18. Hirokawa F, Hayashi M, Asakuma M, Shimizu T, Inoue Y, Uchiyama K. Risk factors and patterns of early recurrence after curative hepatectomy for hepatocellular carcinoma. Surg Oncol. 2016;25(1):24-29.

19. Shindoh J, Andreou A, Aloia TA, et al. Microvascular invasion does not predict long-term survival in hepatocellular carcinoma up to $2 \mathrm{~cm}$ : reappraisal of the staging system for solitary tumors. Ann Surg Oncol. 2013;20(4):1223-1229.

20. Scholzen T, Gerdes J. The Ki-67 protein: from the known and the unknown. J Cell Physiol. 2000;182(3):311-322.

21. Niikura N, Sakatani T, Arima N, et al. Assessment of the Ki67 labeling index: a Japanese validation ring study. Breast Cancer. 2016;23(1): 92-100.

22. Luo Y, Ren F, Liu Y, et al. Clinicopathological and prognostic significance of high Ki-67 labeling index in hepatocellular carcinoma patients: a meta-analysis. Int J Clin Exp Med. 2015;8(7):10235-10247.

23. Inari H, Suganuma N, Kawachi K, et al. Clinicopathological and prognostic significance of Ki-67 immunohistochemical expression of distant metastatic lesions in patients with metastatic breast cancer. Breast Cancer. 2017;24(6):748-755.
24. King KL, Hwang JJ, Chau GY, et al. Ki-67 expression as a prognostic marker in patients with hepatocellular carcinoma. J Gastroenterol Hepatol. 1998;13(3):273-279.

25. Maeda T, Takenaka K, Adachi E, et al. Small hepatocellular carcinoma of single nodular type: a specific reference to its surrounding cancerous area undetected radiologically and macroscopically. J Surg Oncol. 1995;60(2):75-79.

26. Cao Y, Jiang Z, Wang S, Zhang H, Jiang Y, Lv L. Prediction of longterm survival rates in patients undergoing curative resection for solitary hepatocellular carcinoma. Oncol Lett. 2018;15(2):2574-2582.

27. Yang CK, Yu TD, Han CY, et al. Genome-Wide Association Study of MKI67 Expression and its Clinical Implications in HBV-Related Hepatocellular Carcinoma in Southern China. Cell Physiol Biochem. 2017;42(4):1342-1357.

28. Edmondson HA, Steiner PE. Primary carcinoma of the liver: a study of 100 cases among 48,900 necropsies. Cancer. 1954;7(3):462-503.

29. Kawasaki H, Toyoda M, Shinohara H, et al. Expression of survivin correlates with apoptosis, proliferation, and angiogenesis during human colorectal tumorigenesis. Cancer. 2001;91(11):2026-2032.

30. Modi TG, Chalishazar M, Kumar M. Expression of Ki-67 in odontogenic cysts: A comparative study between odontogenic keratocysts, radicular cysts and dentigerous cysts. J Oral Maxillofac Pathol. 2018; 22(1):146.

31. Ahmed A, Al-Tamimi DM. Incorporation of p-53 mutation status and Ki-67 proliferating index in classifying Her2-neu positive gastric adenocarcinoma. Libyan J Med. 2018;13(1):1466573.

32. Pang RW, Joh JW, Johnson PJ, Monden M, Pawlik TM, Poon RT. Biology of hepatocellular carcinoma. Ann Surg Oncol. 2008;15(4): 962-971.

33. Yang LY, Fang F, Ou DP, Wu W, Zeng ZJ, Wu F. Solitary large hepatocellular carcinoma: a specific subtype of hepatocellular carcinoma with good outcome after hepatic resection. Ann Surg. 2009;249(1): 118-123.

34. Fielding LP, Fenoglio-Preiser CM, Freedman LS. The future of prognostic factors in outcome prediction for patients with cancer. Cancer. 1992;70(9):2367-2377.

35. Foltyn W, Zajęcki W, Marek B, et al. The value of the Ki-67 proliferation marker as a prognostic factor in gastroenteropancreatic neuroendocrine tumours. Endokrynol Pol. 2012;63(5):362-366.

36. Johannessen AL, Torp SH. The clinical value of Ki-67/MIB-1 labeling index in human astrocytomas. Pathol Oncol Res. 2006;12(3): 143-147.

37. Zeng W, Gouw AS, van den Heuvel MC, et al. Hepatocellular carcinomas in cirrhotic and noncirrhotic human livers share angiogenic characteristics. Ann Surg Oncol. 2010;17(6):1564-1571.

38. Ammendola M, Sacco R, Marech I, et al. Microvascular density and endothelial area correlate with Ki-67 proliferative index in surgicallytreated pancreatic ductal adenocarcinoma patients. Oncol Lett. 2015; 10(2):967-971
OncoTargets and Therapy

\section{Publish your work in this journal}

OncoTargets and Therapy is an international, peer-reviewed, open access journal focusing on the pathological basis of all cancers, potential targets for therapy and treatment protocols employed to improve the management of cancer patients. The journal also focuses on the impact of management programs and new therapeutic agents and protocols on
Dovepress

patient perspectives such as quality of life, adherence and satisfaction. The manuscript management system is completely online and includes a very quick and fair peer-review system, which is all easy to use. Visit http://www.dovepress.com/testimonials.php to read real quotes from published authors. 